\title{
Influências Ambientais e Inovação de Produtos: Estudo de Casos em Subsidiárias de Multinacionais no Brasil
}

\author{
Dirk Michael Boehe \\ Paulo Antônio Zawislak
}

\section{Resumo}

Este artigo busca identificar e entender as influências do ambiente no processo de inovação de produtos e propor um modo de classificar estas diferentes formas de influências. A inovação em produtos requer capacidades tecnológicas e estas resultam de processos de aprendizagem. Contrastando as perspectivas que tratam de processos internos de aprendizagem, este artigo enfoca estímulos externos que impulsionam e sustentam esses processos. A principal contribuição consiste na classificação de diferentes tipos de estímulos externos, que podem ser atribuídos a três categorias: o ambiente operacional, o ambiente institucional e o ambiente corporativo da subsidiária. Da combinação desses ambientes resulta uma tipologia com oito categorias, as quais serão ilustradas, usando evidências empíricas de subsidiárias localizadas no Brasil. Como segunda contribuição deste estudo, será explorada a possibilidade de reforço mútuo dos estímulos desses três ambientes. Quando houver uma combinação sinérgica entre eles, mais sustentáveis serão as atividades inovadoras da subsidiária ao longo do tempo. Nesse sentido, a análise de mudanças nos três ambientes pode explicar por que as atividades inovadoras da subsidiária têm sido reduzidas, eliminadas ou ampliadas.

Palavras-chave: desenvolvimento do produto; subsidiárias de empresas multinacionais; tipologia; ambiente organizacional.

\begin{abstract}
The objective of this study is to identify and understand the influences of the organizational environment on the process of product innovation as well as to propose a scheme to classify these different forms of influences. Product innovations are based on a firm's technological capabilities which, in turn, result from organizational learning processes. Contrasting approaches which study internal learning processes, this article focuses on external stimuli for innovation from the subsidiary's organizational environment - namely, the task, institutional and corporate environment. Combining these three organizational environments results in a typology of eight different categories which we illustrate using case examples of subsidiaries located in Brazil. In addition, we explore the hypothesis that the mutual reinforcement of stimuli from several environment categories contribute to the sustainability of a subsidiary's innovative activities. Thus, observing changes in these three environments may help to explain why the subsidiary's innovative activities are reduced, eliminated or enhanced.
\end{abstract}

Key words: product development; subsidiaries of multinational companies; typology; organizational environment. 


\section{INTRODUÇÃO}

Embora a inovação dentro das empresas multinacionais em seus países de origem seja amplamente discutida, o mesmo não pode ser dito quanto às suas subsidiárias, especialmente aquelas localizadas em países ditos periféricos, distantes dos principais centros de Ciência e Tecnologia (C\&T). Assim, o presente artigo busca identificar e entender as influências do ambiente no processo de inovação de produtos e propor um modo de classificar estas diferentes formas de influências. É notório perceber que diferentes perspectivas podem dar conta de diferentes fatores explicativos.

Uma das perspectivas mais difundidas visa analisar o âmbito interno da empresa. A inovação tecnológica pode ser vista como resultado de processos de aprendizagem, que permitem transformar baixas capacidades tecnológicas em altas ao longo do tempo ${ }^{(1)}$. A literatura sobre capacidades tecnológicas em países de industrialização recente tem mostrado que empresas do mesmo setor, expostas ao mesmo ambiente externo, podem ter desempenhos bem distintos quanto à velocidade e à profundidade de capacitação tecnológica (Figueiredo, 2003). Ainda sob a mesma perspectiva, estudos realizados em países industrializados sugerem que as subsidiárias podem conquistar papéis de destaque dentro da organização das multinacionais, se sua gerência for empreendedora e, deste modo, tome iniciativas junto à matriz (Birkinshaw, 1996).

Essa perspectiva, no entanto, arrisca relegar o ambiente externo da organização a segundo plano. Contudo existem várias abordagens teóricas que destacam a relevância do ambiente externo, tais como a teoria da contingência, a ecologia organizacional, a do paradigma Structure-Conduct-Performance, dentre outras. Em virtude disso, neste estudo será adotada a segunda perspectiva, que dá prioridade aos estímulos externos à organização, que são vistos como impulsionadores e canalizadores das atividades inovadoras dentro das subsidiárias.

Os estímulos externos são comumente associados ao mercado. Nelson e Winter (1982) reconheceram a importância do feedback do mercado como iniciador das rotinas de busca da empresa. $\mathrm{O}$ processo de aprendizagem incremental nasce a partir dessas rotinas.

Sem dúvida, o fenômeno abstrato do mercado é um estímulo para inovação, mas não é o único. A principal contribuição deste artigo consiste na classificação de diferentes tipos de estímulos externos para a inovação. Esses tipos podem ser 
atribuídos a três categorias genéricas: (i) ambientes corporativo, (ii) operacional e (iii) institucional da subsidiária.

(i) O ambiente corporativo é constituído pelas unidades da multinacional no exterior, como a matriz e as demais subsidiárias.

(ii) $\mathrm{O}$ ambiente institucional refere-se a incentivos do país anfitrião que instigam ou desestimulam atividades inovadoras, afetando a relação custo-benefício da inovação.

(iii) Estímulos inovadores do ambiente operacional dizem respeito a relações entre a empresa e seus clientes, fornecedores, universidades e institutos de pesquisa. Essas relações também podem dar impulsos aos processos internos de aprendizagem.

Relações entre tais diferentes tipos de estímulos externos, por sua vez, ainda carecem de investigação acadêmica, o que se evidencia pelo pequeno volume de literatura sobre o tema. Como segunda contribuição deste estudo, será explorada a possibilidade de reforço mútuo dos estímulos desses três ambientes. O principal argumento é de que este reforço mútuo aumente a sustentabilidade das atividades inovadoras, podendo até implicar a contribuição para projetos globais de inovação da multinacional. Caso contrário, é provável que a subsidiária reduza suas atividades inovadoras.

Os diferentes tipos de estímulos externos, provenientes dos ambientes da empresa, serão introduzidos na próxima seção. Na terceira seção, propomos um esquema de classificação cujos elementos serão ilustrados, usando exemplos de subsidiárias de empresas multinacionais no Brasil. Dedicamos as considerações finais a duas questões: à discussão de possíveis interligações entre os três elementos e à dinamização do esquema de classificação.

\section{Esquema Analítico}

Nesta seção descrevemos as características dos três ambientes (corporativo, institucional e operacional) com seus estímulos à inovação. Mais adiante, será argumentado que as influências dos três ambientes podem fortalecer-se mutuamente como sugere a Figura 1. 


\section{Figura 1: Estímulos para a Capacitação Tecnológica das Subsidiárias}

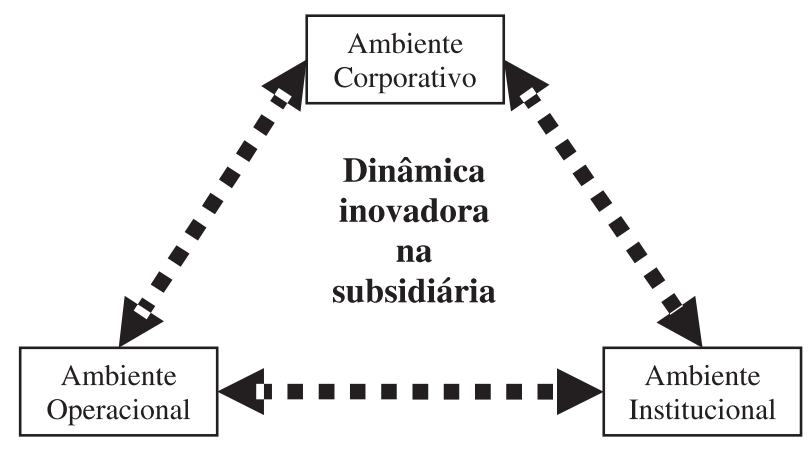

\section{Ambiente Corporativo}

O ambiente corporativo refere-se às relações com organizações que pertencem à multinacional, como outras subsidiárias ou a própria matriz. Os estímulos à inovação do ambiente corporativo estão intimamente atrelados ao modo de coordenação das atividades de desenvolvimento de produto (DP) dentro da empresa multinacional. Do modo de coordenação dependem intensidade e profundidade das trocas de conhecimento tecnológico entre as diversas unidades de DP, as possibilidades de as subsidiárias participar em projetos globais de DP e, sobretudo, a autonomia das subsidiárias para implantar estratégias próprias de capacitação tecnológica.

O modo de coordenação depende da distribuição de laboratórios, equipamentos e conhecimento na corporação: eles podem estar centralizados, descentralizados, duplicados ou não-duplicados. Logo, podemos distinguir três modos distintos de coordenação: a centralização, a descentralização colaborativa e a descentralização competitiva. Esses três modos não são os únicos mencionados na literatura acadêmica (ex. Gassmann \& Zedtwitz, 1999, 2003), mas os consideramos como tipos ideais, cujas características podem misturar-se em algumas empresas.

O modo de coordenação centralizado implica que a maior parte da infraestrutura e das atividades de DP está concentrada no país de origem da multinacional. As decisões sobre as atividades de DP em subsidiárias, se existem, são tomadas unilateralmente pela matriz e não há transferência de conhecimento estratégico e de fronteira para as subsidiárias. A hierarquia burocrática é preponderante e não provê incentivos, para que as unidades de menor nível hierárquico, como as subsidiárias, inovem. Portanto é pouco provável que as 
etapas mais estratégicas de projetos de DP sejam atribuídas às subsidiárias. Este modo de coordenação corresponde ao modelo etnocêntrico (Gassmann \& Zedtwitz, 1999); é considerado o modo predominante de coordenação que se deve a razões históricas, instituições e ideologias do país de origem (Doremus, Keller, Pauly, \& Reich, 1998).

A descentralização cooperativa é caracterizada pela interdependência entre as unidades de DP, pois no estado ideal deste modo de coordenação, não há duplicação de infra-estrutura nas diferentes unidades de DP da multinacional. Cada uma das diferentes etapas do processo de desenvolvimento de um novo produto será realizada na subsidiária que possua o maior conhecimento e a infra-estrutura mais adequada. Conseqüentemente, há uma alta especialização das diferentes unidades de DP e, em algumas empresas, as unidades de maior nível de capacitação tecnológica são elevadas a centros de excelência. Em outras palavras, quando uma unidade de DP em uma subsidiária desenvolve capacidades tecnológicas próprias, a direção dos fluxos de conhecimento pode ser invertida, indo da periferia para o centro da multinacional (Gupta \& Govindarajan, 1991). Este modo de coordenação corresponde ao modelo da rede integrada (Gassmann \& Zedtwitz, 1999). Nesse caso, a troca de conhecimento e de tecnologias é intensa e todas as subsidiárias possuem acesso aos acervos de conhecimento acumulados pela empresa. A autonomia de decisão tende a ser maior do que no modo de coordenação centralizado, mas ela é restrita na medida em que uma subsidiária participa em projetos globais coordenados centralmente.

A descentralização competitiva, ainda pouco explorada pela literatura, usa um mecanismo de coordenação que se baseia fortemente em incentivos econômicos para gerar inovação. Esse mecanismo corresponde, em parte, ao que Birkinshaw e Fey (2000) chamam sistema de mercado interno. Como as diversas unidades de DP possuem capacidades tecnológicas e infra-estruturas semelhantes, novos projetos, responsabilidades e recursos tendem a ser alocados às unidades segundo seu desempenho e custo operacional. Em virtude disto, cria-se uma competição entre as diversas unidades de DP.

Este modo de coordenação pode pendular entre dois extremos: de um lado, pode-se assemelhar ao mecanismo de mercado e, de outro, a coordenação pode ficar centralizada nas mãos da matriz, que avalia as subsidiárias com base em métricas de custo e desempenho. Logo, uma unidade bem avaliada pela matriz, ou pelo sistema de mercado interno, atrairá mais projetos e recursos e, por conseguinte, terá mais oportunidades para se capacitar tecnologicamente. 
Comparando a descentralizarão competitiva e cooperativa com a centralização, nota-se que os critérios segundo os quais a matriz avalia as unidades tendem a ser mais objetivos: desempenho, custo, disponibilidade de infra-estrutura e conhecimento específico. O que há por trás desses três modos de coordenação? $\mathrm{Na}$ essência, é o antigo antagonismo entre hierarquia de um lado, e mercado de outro. Dois extremos em cujo meio se encontra uma forma híbrida, a descentralização cooperativa ${ }^{(2)}$.

\section{Ambiente Institucional}

A análise do ambiente institucional aqui realizada baseia-se na abordagem econômica, segundo a qual o ambiente institucional diz respeito ao conjunto de regras explícitas e implícitas que "definem e limitam o conjunto de escolhas de indivíduos" (North, 1990, p. 4). Sob esta ótica, o ambiente institucional tem alta relevância para a inovação tecnológica, pois "os tipos de conhecimento, habilidades e aprendizagem que os membros de uma organização vão adquirir refletirão os incentivos embutidos no ambiente institucional" (North, 1990, p. 74). Esta abordagem parte da premissa de que as organizações buscam ser eficientes, onde a inovação implica lucro extraordinário e o comportamento organizacional está condicionado à busca por uma maior competitividade.

Nesse contexto, normas técnicas e leis de propriedade intelectual ganham relevância global em muitos setores. Assim, normas nacionais específicas tendem a perder em relevância, pois têm de estar em sintonia com as normas internacionais. A abertura à concorrência e a abolição dos monopólios têm resultado em crescente intensidade de competição. A "competição é o incentivo mais básico que afeta o desenvolvimento de capacidades tecnológicas" (Lall, 1992, p. 171).

O ambiente institucional da subsidiária influencia diretamente o custo das atividades de DP. Embora o custo da instalação deste tipo de atividade em países periféricos pareça ser alto em função da aquisição de nova infra-estrutura, verificase que a redução de custos decorrente de características institucionais favoráveis (custo inferior da mão-de-obra, incentivos fiscais, taxa de câmbio, efeitos de escala decorrentes do tamanho do mercado), pode incentivar o seu deslocamento. Daí a importância em avaliar a relação custo-benefício, que é dada pelos incentivos econômicos.

É importante notar, no entanto, que os incentivos do país anfitrião não podem ser analisados de forma isolada. Uma vez que o país anfitrião compete com outros países por investimentos em DP, os incentivos econômicos oferecido por um país devem ser comparados com os de outro. 
A relevância de incentivos para inovação em subsidiárias é controversa, pois grande parte da literatura acadêmica se limita a dois fatores: (i) a oferta de C\&T no país anfitrião e (ii) a necessidade de responder a estímulos específicos do mercado como fatores predominantes para a globalização de DP (Zedtwitz \& Gassmann, 2002). Tendo em vista que a maioria dos estudos nesta área tem origem no mundo industrializado, o custo relativo de desenvolvimento das atividades de DP em diferentes países e os incentivos para reduzi-lo têm sido pouco considerados, sendo o caso da Índia uma exceção (Reddy, 1997).

\section{Ambiente Operacional}

Este estudo parte do pressuposto de que a inovação ocorre cada vez mais em rede e em cooperação com outras organizações ao longo da cadeia de valor. Essa tendência é alicerçada na crescente especialização do conhecimento (Dosi, 1988) e das atividades das empresas. As inovações tornam-se cada vez mais complexas, porquanto disciplinas distintas precisam ser integradas na busca por gerar novos produtos. Assim, o risco e o custo para uma única organização se capacitar em todas as disciplinas necessárias para o desenvolvimento de um novo produto são incrementados, tornando as parcerias indispensáveis para inovar.

O ambiente operacional da unidade de DP de uma empresa abrange o conjunto de parceiros que influenciam as atividades de DP, sejam eles fornecedores ou clientes da empresa, universidades, institutos de pesquisa ou empresas de engenharia. A ausência de parceiros geograficamente próximos ou com acesso a eles dificultado podem explicar por que uma unidade de DP não atinge certo nível de capacitação tecnológica.

A importância dos fornecedores será maior, quando a unidade de DP assumir o papel de integrador de sistemas ou tecnologias e variar de acordo com a contribuição deles para o desenvolvimento de um produto: há aqueles que fornecem componentes muito específicos e outros que fornecem tão somente commodities. Uma vez que componentes muito específicos e complexos são integrados em sistemas de alta tecnologia (como motores, aviões etc.) parcerias estreitas entre as unidades de DP das empresas (cliente, usuário, fornecedor) se tornam imprescindíveis (Dosi, Hobday, Marengo, \& Prencipe, 2002).

Projetos de desenvolvimento em conjunto com os fornecedores implicam o intercâmbio de conhecimento e podem contribuir para o desenvolvimento de produtos mais competitivos. Uma pré-condição para absorver o conhecimento do parceiro consiste no acompanhamento do seu desenvolvimento tecnológico e 
de suas pesquisas científicas (Cohen \& Levinthal, 1990), resultando, assim, um estímulo para a própria capacitação tecnológica.

Os usuários do produto final podem exigir aprimoramentos ou redução do seu custo e, dependendo do caso, participar desde as fases iniciais de conceituação. Além disso, os usuários de bens de capital podem desenvolver modificações do produto que posteriormente serão incorporadas a novos desenhos do fornecedor original (v. Hippel, 1988). Portanto, quanto mais especificas as necessidades dos clientes, maior a importância de sua colaboração com o inovador.

Já aqueles cujas necessidades antecipam as de outros mercados, são chamados lead users (v. Hippel, 1988, p. 107); por exemplo, um produto desenvolvido no Brasil que posteriormente for introduzido em mercados com características semelhantes: países latino-americanos, Europa Oriental, entre outros.

Muitas universidades e institutos realizam pesquisas básicas com a finalidade de gerar novos conhecimentos teóricos, o que já não acontece com empresas, devido ao alto risco e o longo tempo de conclusão deste tipo de atividade. No entanto novos conhecimentos podem gerar novas tecnologias e essas, por sua vez, conduzem a vantagens competitivas para aquelas empresas que os detêm. Em virtude disso, o acesso ao acervo de conhecimento das universidades e institutos de pesquisa é imprescindível para a competitividade a longo prazo da empresa.

Para outras empresas, o principal atrativo da cooperação com universidades e institutos de pesquisa consiste no uso de equipamentos para análises e testes. $\mathrm{O}$ objetivo não está na incorporação de novas tecnologias e, sim, na terceirização dos serviços tecnológicos. Esses são vitais para as atividades inovadoras dessas empresas, uma vez que não possuem todos os equipamentos necessários internamente.

\section{Inovação em Subsidiárias Brasileiras de Empresas Multinacionais}

Conforme exposto anteriormente, a capacitação tecnológica de subsidiárias de empresas multinacionais é influenciada por três ambientes: o corporativo, o institucional e o operacional. Cada um destes três ambientes pode gerar estímulos fortes (+) e fracos (-), os quais, combinados, podem ser agrupados em oito tipos, representados pelas letras de A a $\mathrm{H}$ (conforme Figura 2). 


\section{Figura 2: Classificação de Subsidiárias com Base em Estímulos Externos}

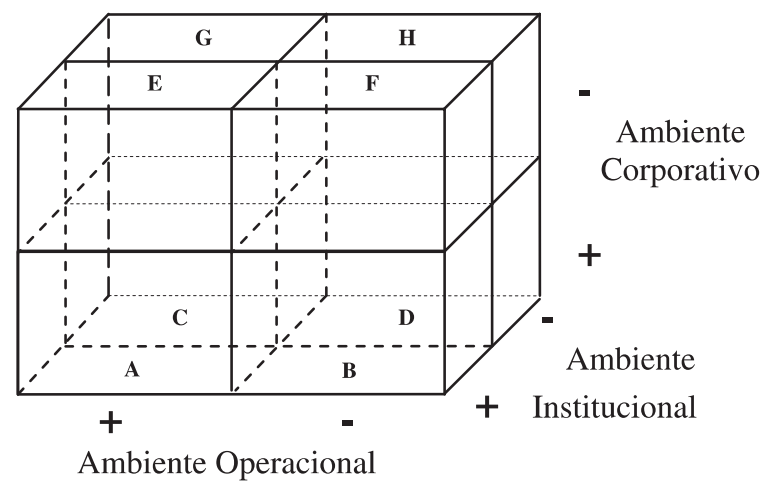

O estudo foi feito com base em mais de 20 subsidiárias de multinacionais, entre novembro de 2001 e outubro 2003 nas regiões Sul e Sudeste do Brasil. Dessas, foram selecionadas oito empresas de diversos ramos industriais que apresentam alta variedade de dados empíricos com características diferenciadas. A escolha de casos com características diferenciadas é recomendada por Pettigrew ${ }^{(3)}$, como citado em Eisenhardt (1989, p. 537). Cinco subsidiárias são de capital originalmente brasileiro e foram adquiridas nas décadas de 1980 e 1990.

Num primeiro momento, as informações foram coletadas através de entrevistas nos departamentos de DP e engenharia de produto. A coleta de dados foi feita junto aos gerentes e diretores, de forma aberta, com base em roteiro preestabelecido. Este foi desenvolvido nos moldes dos conceitos teóricos apresentados na seção anterior e abrange tópicos como natureza, foco das atividades de DP, razões pelas quais a subsidiária realiza DP no Brasil, divisão de trabalho com outros centros de DP da multinacional, relação subsidiáriamatriz, cooperações com parceiros locais e internacionais, grau de instrução dos funcionários, infra-estrutura disponível e importância de incentivos, entre outros.

Segundo as recomendações de Yin (2001) e Eisenhardt (1989), para estudos de casos múltiplos, as características dos casos foram comparadas e observadas a partir de distintos ângulos para identificar padrões (cross-case analysis). Com a finalidade de aumentar a confiabilidade, alguns dos resultados foram confirmados em diferentes entrevistas pessoais e na aplicação de um questionário estruturado após as entrevistas. Algumas entrevistas contaram com a participação de vários pesquisadores. Material secundário como artigos de jornais, revistas e outros trabalhos empíricos também foram usados como fonte de informação. 


\section{Tipo A: Fortes Estímulos dos Ambientes Institucional, Operacional e Corporativo}

Ambiente corporativo. A unidade de tratores e colheitadeiras da Maxion foram adquiridas pela AGCO nos anos 90 . A subsidiária brasileira fez adaptações nessas tecnologias, buscando reduzir o custo do produto e adequando suas características às necessidades locais.

O status da subsidiária mudou a partir do ano 2003, quando a matriz decidiu descontinuar a fábrica na Inglaterra e deslocar as capacidades de produção para o Brasil. Junto com as linhas de montagem chegaram bancas de testes e outros equipamentos que fortalecem as atividades locais de DP. A partir de setembro 2004, a unidade brasileira obtém o status de centro mundial para o desenvolvimento de colheitadeiras tradicionais.

Ambiente institucional. Neste cenário a empresa busca reduzir os seus custos de produção e de desenvolvimento de produto, deslocando atividades para países com menor custo. Com respeito ao custo hora dos projetos de DP, há uma hierarquia dentro da organização da empresa multinacional, estando a Dinamarca com os custos mais elevados, seguida pelos EUA, enquanto no cenário dos países com baixo custo estão o Brasil e a Índia. Em função da desvalorização da taxa de câmbio e dos baixos salários, o Brasil ganhou vantagens de custo. Este cenário faz com que as empresa consigam aumentar o valor da empresa para seus acionistas, produzindo e desenvolvendo o Brasil. Certamente, uma pré-condição para o bom funcionamento dessa estratégia, é a capacitação tecnológica das respectivas subsidiárias.

Outro atrativo do Brasil é o enorme potencial de crescimento da agroindústria em comparação com outros mercados mundiais, a exemplo da Europa. Este crescimento é estratégico na política econômica do país. Existem linhas de financiamento do BNDES para a compra de equipamento agroindustrial, o que permite estimular a demanda por equipamentos produzidos localmente. Ademais, a intensidade de concorrência no mercado brasileiro de equipamentos agroindustriais é forte, fato que estimula a geração de inovações.

Ambiente operacional. Nas palavras do representante dessa empresa, "não existe um trator ou uma colheitadeira global", pois as condições geográficas, topográficas e climáticas influenciam consideravelmente o desenho do produto. Para melhor adequar os produtos às condições locais, a AGCO mantém laços estreitos com os usuários, as instituições de ensino, pesquisa e os seus fornecedores. A existência de uma cadeia quase completa de fornecedores no Brasil é essencial para poder desenvolver seus produtos no país: "hoje, pouco se 
desenvolve e raramente as atividades de DP criam conceitos totalmente novos. Na realidade é o fornecedor que desenvolve a maior parte do novo produto". Por exemplo, somente o motor pode custar em torno de $25 \%$ de um novo trator. A transmissão e a lataria também abrangem parcelas consideráveis do custo do produto. A estreita colaboração com fornecedores no Brasil é, portanto, essencial para desenvolver produtos adequados às exigências dos clientes locais.

Em síntese, os três ambientes reforçam-se mutuamente, no sentido ideal, exemplificado pela Figura 1. O ambiente corporativo, caracterizado pela descentralização e pela competição entre as subsidiárias, incentiva o aproveitamento das vantagens de custo auferidas pelo ambiente institucional brasileiro, e este último promove, por sua vez, a nacionalização da produção e fortalece, portanto, a cadeia de valor existente no Brasil. Afinal, a descentralização das atividades de DP é necessária em função das exigências específicas dos usuários em cada país.

\section{Tipo B: Fortes Estímulos dos Ambientes Institucional e Corporativo, Fracos Estímulos do Ambiente Operacional}

Ambiente corporativo. A Springer Carrier produz e desenvolve condicionadores de ar no Brasil. As atividades de desenvolvimento de produtos são altamente descentralizadas e a preocupação com os custos de desenvolvimento reflete-se nas relações bastante competitivas entre as diferentes unidades de DP no que diz respeito à atribuição de projetos.

Em 1999, a matriz atribuiu ao centro de desenho brasileiro a responsabilidade mundial por uma importante família de produtos da multinacional: condicionadores de ar de janela. Desde o início de 2003, a Springer Carrier está desenvolvendo um projeto global para aparelhos split, destinados a refrigerar ambientes maiores. Este projeto vinha sendo desenvolvido na Itália, mas foi sublocado para o centro de desenho brasileiro.

Ambiente institucional. O ambiente institucional exerce três formas de pressões para inovar: intensidade de concorrência no mercado, regras governamentais e custo relativo. Em primeiro lugar, há forte intensidade de concorrência no setor de condicionadores de ar Brasil. Além da Springer Carrier, líder do mercado, mais de 10 empresas competem de forma agressiva por fatias do mercado brasileiro. Em segundo lugar, o governo brasileiro decretou normas mais restritas, para reduzir o consumo de energia em função do apagão occorido em 2001. Essas exigências geram maior necessidade de testes e certificações no país e incitam ainda mais a concorrência, uma vez que os produtores concorrem a prêmios nacionais por otimização do consumo de energia. Em terceiro lugar, as 
desvalorizações da moeda fizeram com que as atividades de DP realizadas no Brasil se tornassem mais baratas do que em outros países onde a empresa mantém unidades como a Coréia. Como no caso anterior, as pressões dos ambientes institucional e corporativo se complementam e favorecem o Brasil como um local de atividades inovadoras.

Ambiente operacional. Parcerias na área de DP são praticadas, porém elas têm caráter esporádico e não são consideradas vitais para suas atividades. É importante notar que se trata de um produto com componentes maduros, sendo que novos componentes e materiais avançados geralmente são desenvolvidos no centro de pesquisa central da empresa-mãe nos EUA.

\section{Tipo C: Fortes Estímulos dos Ambientes Operacional e Corporativo, Fracos Estímulos do Ambiente Institucional}

Ambiente corporativo. A International Engines South America realiza no Brasil o desenvolvimento de motores diesel de alta velocidade. A empresa, criada pela Perkins nos anos 1950 fez parte de um conglomerado brasileiro até o final dos anos 1990, complementando a gama de produtos da matriz norte-americana, cujo foco são os motores diesel pesados. A complementaridade resultou no fortalecimento das atividades de DP da subsidiária brasileira, tornando o seu motor Diesel de alta velocidade em um produto global. Trata-se de uma descentralização com relações cooperativas entre as unidades de DP.

Ambiente institucional. Tendo um produto global, as normas de emissão dos países mais avançados são relevantes para o desenvolvimento de novos motores, pois "o que move a tecnologia são os regulamentos de emissões". No entanto a defasagem do regulamento brasileiro apenas incentiva o desenvolvimento de versões mais baratas (e, consequientemente, mais poluentes) dos mesmos motores. $\mathrm{O}$ menor custo de desenvolvimento do produto no Brasil não é relevante para a divisão de trabalho entre subsidiária e matriz, mas o que dificulta as atividades de DP é a enorme pressão sobre os custos e a baixa escala de produção no Brasil.

Ambiente operacional. Parcerias no Brasil, com fornecedores de componentes, permite a realização de projetos de desenvolvimento conjunto para os pistões, os anéis, o monobloco ou os sistemas de injeção. A existência de uma cadeia de valor bastante completa no Brasil tem sido crucial para a capacitação tecnológica da empresa e, especificamente, para a criação de capacidades de gestão de projeto em conjunto com fornecedores nacionais e estrangeiros. A presença dos principais clientes (as montadoras de caminhonetes) no Brasil possibilita responder rapidamente às suas exigências. Logo, o status de centro de excelência, concedido pela matriz à subsidiária adquirida, pode ser considerado 
como conseqüência das altas capacidades tecnológicas e dos fortes relacionamentos com clientes e fornecedores locais.

\section{Tipo D: Fortes Estímulos do Ambiente Corporativo, Fracos Estímulos dos Ambientes Operacional e Institucional}

Ambiente corporativo. A subsidiária da GKN Automotive realizava principalmente aplicações para os seus clientes locais. Entretanto a subsidiária norte-americana da empresa sublocou um projeto de desenvolvimento de um novo produto para a filial brasileira, o que indica que a empresa está subindo a escada das capacidades tecnológicas. $O$ gerente da unidade enfatizou que o bom desempenho da unidade em termos de qualidade, custos e atendimento aos clientes locais foi o principal motivo para a obtenção desse projeto. Outro motivo foi a plena ocupação das capacidades de desenvolvimento na subsidiária norteamericana. O custo de desenvolvimento de produto foi considerado pouco relevante para esta sublocação. Como no exemplo anterior, trata-se de uma descentralização cooperativa das atividades de desenvolvimento de produto.

Ambientes operacional. A empresa não pratica parcerias para o desenvolvimento de produto, para manter o sigilo de conhecimento. Além disso, parece que há poucos parceiros adequados para uma tecnologia tão específica.

Ambiente institucional. Incentivos não são aproveitados e os altos juros reprimem a demanda dos principais clientes das empresas, as montadoras de automóveis.

A sustentabilidade do estímulo decorrente do ambiente corporativo e as possibilidades futuras de ser uma unidade de desenvolvimento de produto reconhecida pela matriz dependem da utilização das capacidades existentes de desenvolvimento nas outras subsidiárias localizadas no exterior.

\section{Tipo E: Fortes Estímulos dos Ambientes Operacional e Institucional, Fracos Estímulos do Ambiente Corporativo}

Ambiente corporativo. A Cognis persegue uma estratégia de expansão e busca abrir o capital da empresa nas bolsas em 2004. Além da unidade de DP no Brasil, há maiores centros de DP na Alemanha, na Espanha e nos EUA. A troca de informação entre diversas unidades de DP da empresa, antes quase inexistente, tem melhorado desde os anos 1990; mas, nos últimos anos, os investimentos em DP foram reduzidos. Um dos entrevistados apontou que "existem, nas outras subsidiárias, resistências frente ao trabalho que se faz no Brasil, principalmente, quando um projeto vai daqui para lá”. Por exemplo, é demorado tornar global o 
projeto brasileiro Amazon Care Chemicals em função da burocracia interna da multinacional e dos problemas de imagem de um país periférico perante a matriz.

Ambiente institucional. A divisão de produtos de beleza começou a criar componentes químicos para xampus, cremes com base de óleos naturais da Amazônia, como castanha, pequi e cupuaçu. No Brasil, a Cognis é a primeira empresa que usa esses óleos como matéria prima e os compra de comunidades indígenas. $\mathrm{O}$ aproveitamento comercial da biodiversidade da Amazônia é realizado de forma sustentável, cuidando o meio ambiente e as características sociais das comunidades indígenas. Esta prática é reconhecida pelo Banco Mundial e aprovado pelo IBAMA e indica forte entrelaçamento institucional da subsidiária.

É notável que essa estratégia se complementa com a estratégia de crescimento de longo prazo da empresa multinacional. Para abrir o capital nas bolsas é imprescindível cultivar uma imagem de sustentabilidade ambiental e social. Assim, atuando conforme as regras do jogo, é possível explorar novas oportunidades tecnológicas e, ao mesmo tempo, realizar os objetivos estratégicos.

Ambiente operacional. O ambiente operacional é favorável, porque os principais clientes globais da empresa multinacional operam no Brasil. Desenvolvimento em conjunto com importantes clientes brasileiros, como a Natura, tem sido importante para desenvolver o projeto Amazon Care Chemicals. Além disso, institutos de pesquisa e universidades com infra-estrutura de nível mundial, no Estado de São Paulo, permitem a terceirização de uma fração crescente dos serviços tecnológicos e das atividades de DP. O uso da infra-estrutura das universidades permite a Cognis realizar projetos completos de DP a baixo custo. Ademais, a realização de cursos de pós-graduação por vários funcionários aumenta a capacidade de absorção de conhecimento (Cohen \& Levinthal, 1990). Há, então, uma boa sintonia entre os estímulos dos ambientes institucional e operacional, mas é evidente que o ambiente corporativo ainda limita o potencial da unidade de DP no Brasil.

\section{Tipo F: Fortes Estímulos do Ambiente Institucional, Fracos Estímulos dos Ambientes Operacional e Corporativo}

Ambiente corporativo. O centro brasileiro DP tem responsabilidades mundiais de desenvolvimento de software para uma plataforma de comutação telefônica global. Recentemente, entretanto, os investimentos foram reduzidos em função da crise no setor de telecomunicações a partir de 2001. A política da matriz de exercer um 'controle extraordinário' sobre as atividades de DP das suas subsidiárias (Nobel \& Birkinshaw, 1998, p. 491) limita a autonomia de decisão das subsidiárias. Mas, ao mesmo tempo, a matriz incentiva a competição entre as 
diferentes subsidiárias descentralizadas; é por isso que o ambiente corporativo da Ericsson já foi caracterizado como um 'mercado interno' (Birkinshaw \& Fey, 2000). Nesse mercado interno, o desempenho das diversas unidades de DP em termos de custo, qualidade e time-to-market é o critério prevalecente para a atribuição de projetos.

Ambiente institucional. O principal fator que permitiu, em 2000, estabelecer um centro de DP para desenvolvimento de software foram os incentivos da Lei da Informática. Esta exigia o investimento de cinco por cento do faturamento bruto em DP. Em função do elevado faturamento bruto da subsidiária nos tempos do boom entre o final dos anos 1990 e 2001, a lei criou um grande volume de capacidades para atividades de DP no Brasil: em 2001 foram investidos quase R\$ 150 milhões em DP e o centro em Indaiatuba empregava em torno de 500 funcionários. Para preencher essas capacidades e para aproveitar as vantagens do baixo custo em comparação com países de alto custo, foram atraídos projetos de desenvolvimento de software de outras subsidiárias. Entretanto o faturamento encolheu devido à crise mundial no setor de telecomunicações e ao preenchimento das metas de universalização no Brasil. Conseqüentemente, os investimentos em DP foram reduzidos a algo como R\$ 60 milhões em 2003, enquanto o centro ainda empregava em torno de 250 funcionários.

Ambiente operacional. Praticamente todos os projetos de desenvolvimento têm caráter global e são realizados em conjunto com outras subsidiárias da empresa no exterior. Parceiros locais são irrelevantes para projetos de desenvolvimento de software. Os projetos de pesquisa realizados com universidades e institutos de pesquisa não têm vínculos com os projetos de desenvolvimento de software e, para alguns deles, a matriz na Suécia é o principal interlocutor.

Enquanto o ambiente operacional é irrelevante, o ambiente institucional apresenta vantagens de custo em função dos benefícios da Lei da Informática e da desvalorização da moeda brasileira. O ambiente corporativo, embora pouco estimulante em função da recente crise da empresa, permite que as vantagens em custo de desenvolvimento de software da subsidiária brasileira possam ser traduzidas em atribuições de projetos e responsabilidades globais.

\section{Tipo G: Fortes Estímulos do Ambiente Operacional, Fracos Estímulos dos Ambientes Institucional e Corporativo}

Ambiente Corporativo. A unidade brasileira de engenharia do produto da Dana-Spicer é uma de quatro centros de DP para cardans. Os outros centros são localizados nos EUA, na Alemanha e no Japão onde são concentradas as principais atividades de desenvolvimento de novos produtos. A sublocação de 
tarefas de outras subsidiárias para a unidade brasileira está sendo praticada em função do custo favorável, mas restringe-se a validações de produtos.

Ambiente institucional. O custo mais favorável não parece incentivar atividades de desenvolvimento de novos produtos. Um mercado com baixas taxas de crescimento, e o fato de que a empresa é quase monopolista no segmento de mercado de cardans para veículos pesados parecem limitar os incentivos à inovação local.

Ambiente operacional. Os estímulos do ambiente operacional brasileiro foram debilitados nos últimos anos. Recentemente, algumas montadoras, os principais clientes da empresa, tornaram a centralizar as suas atividades de desenvolvimento do produto. A Volkswagen, por exemplo, transferiu algumas atividades de desenvolvimento de produtos do Brasil para a matriz na Alemanha. E, em 2002, a DaimlerChrysler do Brasil deixou de desenvolver caminhões para o mercado latino-americano a favor de produtos globais desenvolvidos exclusivamente na matriz. Logo, as atividades de desenvolvimento conjunto com as montadoras têm sido enfraquecidas.

Mesmo assim, a unidade brasileira realiza desenvolvimento de produto para clientes do mercado local como as divisões de caminhões da DaimlerChrysler ou da Volkswagen. No caso da DaimlerChrysler, a parceria possui alto valor estratégico, pois o objetivo é evitar que outros fornecedores entrem no mercado brasileiro. Para tanto, a Dana-Spicer busca oferecer seus produtos a preços que inviabilizariam a entrada no mercado do concorrente; ademais, está sempre disposta a realizar adaptações dos seus produtos às exigências dos seus clientes estratégicos.

A divisão de caminhões da Volkswagen apresentou forte crescimento que se deve, principalmente, à estratégia de oferecer caminhões de baixo preço e adaptados às exigências de cada usuário final. Conseqüentemente, os fornecedores, como a Dana-Spicer, precisam desenvolver produtos que se adéquam à estratégia de customização da Volkswagen, respondendo a necessidades específicas do cliente final. Resumindo, o ambiente operacional é praticamente a única fonte de estímulos para a realização de DP no Brasil.

\section{Tipo H: Fracos Estímulos dos Ambientes Institucional, Operacional e Corporativo}

Ambiente corporativo. A Alcatel tinha um centro de DP em Campinas até 2000. A desativação devia-se, em primeiro lugar, a uma mudança estratégica da matriz; esta decidiu reduzir o número de centros de DP de 23 para 5 no mundo 
inteiro. Essa decisão é o resultado da tendência para produtos globais, devido às rápidas mudanças tecnológicas na indústria de telecomunicações e da crescente dificuldade de justificar altos investimentos em DP diante dos acionistas das empresas.

Ambiente institucional. Em função da globalização do setor, hoje, o ambiente institucional tornou-se predominantemente global. Os padrões técnicos deixam de ser nacionais: se os líderes tecnológicos mundiais chegam a um acordo sobre um novo protocolo tecnológico, então esse protocolo tende a virar padrão para o mundo inteiro.

Quanto ao ambiente institucional nacional, as metas de universalização impostas pela agência reguladora, ANATEL, constituíam um dos principais fatores que impulsionaram a demanda local. No entanto, atingidas essas metas, um dos principais sustentáculos da demanda interna foi eliminado. A forte concorrência no mercado brasileiro, devido à presença dos principais global players da indústria de telecomunicações, limitou ainda mais as possibilidades de atingir altas escalas de produção.

Ao estourar o boom da nova economia, o cancelamento de pedidos em 2001 resultou na desativação da fábrica brasileira. Apesar de ser uma fábrica de última geração, ela já não era competitiva, pois os custos de produção em outros países, como a China ou a Índia, eram ainda mais baixos. A desativação da fábrica traduziu-se no desvanecimento dos recursos para DP, decorrentes da Lei da Informática: sem processo de produção básico (PPB) no Brasil, a empresa não qualificou mais para obter os incentivos (redução do IPI) e também não estava obrigada a investir uma fração do faturamento em DP no Brasil.

Ambiente operacional. Padrões tecnológicos globais significam que cada vez há menos necessidade de adaptar produtos para necessidades específicas de clientes locais. Quanto aos fornecedores, é importante notar que a tendência na indústria de telecomunicações é terceirizar a produção (Sturgeon, 2000); portanto é cada vez menos provável que a fábrica seja reaberta, caso a demanda interna se reative, fato que elimina a necessidade de interações com fornecedores.

Em suma, os estímulos negativos dos três ambientes inviabilizaram as atividades inovadoras da subsidiária brasileira. 


\section{Considerações Finais}

Sugerimos por meio da análise de oito exemplos que combinações diferentes entre estímulos dos três ambientes podem expressar-se em graus diferentes de sustentabilidade das atividades inovadoras. Tomando o esquema de classificação (Figura 2) como base, é evidente que as atividades inovadoras fiquem mais sustentáveis e intensas, quando os estímulos positivos para inovação estiverem ancorados nos três ambientes (tipo A). Em outras palavras, os estímulos dos três ambientes podem reforçar-se mutuamente. Quanto maior o número de estímulos que se reforçam mutuamente, maior será a sustentabilidade e o potencial futuro das atividades de DP da subsidiária.

Todavia é preciso notar que não parece haver uma relação entre a sustentabilidade dos estímulos e o papel da subsidiária na multinacional. Por exemplo, a Ericsson e a AGCO possuem responsabilidades globais em DP, mas os estímulos da AGCO (tipo A) são bem mais sustentáveis do que os estímulos da Ericsson (tipo F).

$\mathrm{Na}$ ausência de estímulos positivos, no entanto, é provável a redução e até mesmo a desativação de atividades inovadoras (tipo H). Quando as atividades inovadoras da subsidiária dependem de estímulos originados tão-somente em um único ambiente, a sustentabilidade das atividades de DP pode estar ameaçada, pois pequenas mudanças nesses ambientes podem levar à eliminação ou redução dos estímulos. Os exemplos da GKN (tipo D), da Ericsson (tipo F) e da DanaSpicer (tipo G) ilustram a iminência desses riscos: no ambiente institucional, a redução dos incentivos tributários (Ericsson), no ambiente operacional, mudanças estratégicas dos principais clientes da Dana-Spicer e, no ambiente corporativo, o surgimento de capacidades ociosas em desenvolvimento de produto nas outras subsidiárias da GKN, localizadas no exterior, podem esmorecer os estímulos existentes.

Logo, é importante notar que os ambientes podem mudar de uma situação favorável para uma situação menos favorável e vice-versa. Os seguintes exemplos de mudanças ilustram essa idéia. Embora o ambiente corporativo da Cognis ainda não possa ser considerado como forte estímulo para DP, ele tem melhorado nos últimos anos: hoje são compartilhadas mais informações e conhecimento entre as subsidiárias do que no passado. Ou seja, os estímulos desse ambiente corporativo têm passado de negativos para neutros.

O ambiente institucional da AGCO e da Springer Carrier, por exemplo, mudou de pouco favorável nos anos anteriores a 1998 para bastante favorável a partir 
de 1999, em razão das desvalorizações da moeda brasileira. Preços relativos mais baixos aumentaram a competitividade da unidade de DP brasileira em face das suas irmãs localizadas em outros países.

Sem dúvida, o ambiente operacional da Ericsson e da Alcatel tem piorado desde o início dos anos 1990. Muitos elementos da cadeia de valor (indústria de componentes eletro-eletrônicos), que tinham sido criados nos tempos da reserva de mercado, foram praticamente eliminados em função de uma abertura abrupta do mercado brasileiro, da mudança na política de compras das empresas prestadoras de telefonia e da sobrevalorização da moeda brasileira entre 19941998. Logo, as atividades de desenvolvimento e adaptação de hardware foram inviabilizadas no Brasil.

Estímulos ambientais explicam, assim sugerem os nossos exemplos, a realização ou não de atividades inovadoras em subsidiárias. Esta conclusão afirma que a segunda perspectiva apresentada na introdução é uma abordagem analítica válida e importante. Mas isto não invalida a primeira perspectiva; pelo contrário, o desafio para futuras pesquisas consiste justamente na combinação de ambas as abordagens, ou seja, na análise aprofundada das relações entre inovação, processos internos de aprendizagem e estímulos externos.

Essas reflexões podem ser aproveitadas pelos gestores da política de C\&T e das próprias subsidiárias para desenhar estratégias que abram mais oportunidades para DP em subsidiárias de multinacionais, porque a política pública possui instrumentos para influenciar algumas variáveis dos ambientes operacional e institucional. Já, em relação aos gestores das empresas, é importante assinalar que as subsidiárias não são elementos passivos sujeitos à determinação dos três ambientes. Elas possuem a opção de conceber suas próprias estratégias, visando identificar e aproveitar as oportunidades existentes nos seus ambientes. Se a matriz permitir, a estratégia da subsidiária pode refinar o foco e a natureza das atividades inovadoras, a fim de inserir-se em um conjunto mais favorável de ambientes.

\section{Artigo recebido em 16.09.2004. Aprovado em 29.11.2004.}

\section{NotAs}

${ }^{1}$ Lall (1992) e Figueiredo (2003) concebem as capacidades tecnológicas da empresa como uma escada que inicia com capacidades rotineiras, passa por capacidades inovadoras e culmina com capacidades tecnológicas avançadas, baseadas na Ciência. Enquanto as capacidades rotineiras se 
limitam à reprodução de especificações técnicas pré-definidas, as capacidades tecnológicas avançadas dizem respeito à geração de conhecimento totalmente inédito.

${ }^{2}$ Esses três modos de coordenação assemelham-se aos três tipos de governança cunhados por Williamson (1991), mas suas premissas são distintas.

${ }^{3}$ Pettigrew, A. Longitudinal field research in change: theory and practice. Paper presented at the National Science Foundation Conference on Longitudinal Research Methods in Organizations, Austin, 1988.

\section{ReferênCIAs Bibliográficas}

Birkinshaw, J. (1996).

How multinational subsidiary mandates are gained and lost. Journal of International Business Studies, 27(3), 467-496.

Birkinshaw, J., \&

Fey, C. (2000).

Building an internal market system: insights from five R\&D organizations. In J. Birkinshaw, \& P. Hagstrom (Eds.). The flexible firm: capability management in network organizations (pp. 149-175). Oxford, New York: Oxford University Press.

Cohen, W., \&

Levinthal, D. (1990).

Absorptive capacity: a new perspective on learning and innovation. Administrative Science Quarterly, 35(1), 128-153.

Doremus, P.,

Keller, W.,

Pauly, L., \&

Reich, S. (1998).

The myth of the global corporation.

Princeton: Princeton University Press.
Dosi, G. (1988).

The nature of the innovative process. In G. Dosi, C. Freeman, R. Nelson, G. Silverberg, \& L. Soete. Technical change and economic theory (pp. 221237). London: Pinter.

Dosi, G.,

Hobday, M.,

Marengo, L., \&

Prencipe, A. (2002).

The economics of system integration: toward an evolutionary interpretation. LEM [Working Paper Series]. Laboratory of Economics and Management, Sant'Anna School of Advanced Studies, Pisa, 16. Recuperado em 5 dezembro, 2006, de http://www.lem.sssup.it/WPLem/ files/2002-16.pdf

Eisenhardt, K. (1989).

Building theories from case study research. Academy of Management Review, 14(4), 532-551.

Figueiredo, P. N. (2003).

Aprendizagem tecnológica $e$ performance competitiva (L. A. Monjardim, Trad.). Rio de Janeiro: Editora FGV. (Obra original publicada 2001). 
Gassmann, O., \&

Zedtwitz, M. V. (1999).

New concepts and trends in international R\&D organization. Research Policy, 28(2-3), 231-250.

Gassmann, O., \&

Zedtwitz, M. V. (2003).

Trends and determinants of virtual $\mathrm{R} \& \mathrm{D}$ teams. $R \& D$ Management, 33(3), 243-263.

Gupta, A., \&

Govindarajan, V. (1991).

Knowledge flows and the structure of control within multinational corporations. Academy of Management Review, 16(4), 768-792.

Hippel, E. V. (1988).

The sources of innovation. New York: Oxford University Press.

Lall, S. (1992).

Technological capabilities and industrialization. World Development, 20(2), 165-186.

Nelson, R., \&

Winter, S. (1982).

An evolutionary theory of economic change. Cambridge, MA: Belknop Press.

Nobel, R., \&

Birkinshaw, J. (1998).

Innovation in multinational corporations: control and communication patterns in international R\&D operations.
Strategic Management Journal, 19(5), 479-496.

North, D. (1990).

Institutions, institutional change and economic performance. Cambridge: Cambridge University Press.

Reddy, P. (1997).

New trends in globalization of corporate R\&D and implications for innovation capability in host countries: a survey from India. World Development, 25(11), 1821-1837.

Sturgeon, T. (2000).

Turnkey production networks: the organizational delinking of production from innovation. In U. Jürgens (Ed.). New product development and production Networks (pp. 67-84.). Berlin: Springer.

Yin, R. (2001).

Estudo de caso - planejamento e métodos (2a ed.). Porto Alegre: Bookman.

Williamson, O. W. (1991).

Comparative economic organization: the analysis of discrete structural alternatives. Administrative Science Quarterly, 36(2), 269-296.

Zedtwitz, M. V., \&

Gassmann, O. (2002).

Market versus technology drive in R\&D internationalization: four different patterns of managing research and development. Research Policy, 31(4), 31, 569-588. 
